Johnson \& Wales University ScholarsArchive@JWU

Health \& Wellness Department Faculty

Publications and Research

College of Health \& Wellness

$3-2017$

\title{
Associations between thematic content and industry self-regulation code violations in beer advertising broadcast during the U.S. NCAA basketball tournament
}

Jonathan K. Noel

Johnson \& Wales University - Providence, Jonathan.Noel@jwu.edu

Ziming Xuan

Thomas F. Babor

Follow this and additional works at: https://scholarsarchive.jwu.edu/health_fac

Part of the Medicine and Health Sciences Commons

\section{Repository Citation}

Noel, Jonathan K.; Xuan, Ziming; and Babor, Thomas F., "Associations between thematic content and industry self-regulation code violations in beer advertising broadcast during the U.S. NCAA basketball tournament" (2017). Health \& Wellness Department Faculty Publications and Research. 38.

https://scholarsarchive.jwu.edu/health_fac/38

This Article is brought to you for free and open access by the College of Health \& Wellness at ScholarsArchive@JWU. It has been accepted for inclusion in Health \& Wellness Department Faculty Publications and Research by an authorized administrator of ScholarsArchive@JWU. For more information, please contact jcastel@jwu.edu. 
Substance Use \& Misuse

\title{
Associations Between Thematic Content and Industry Self-Regulation Code Violations in Beer Advertising Broadcast During the U.S. NCAA Basketball Tournament
}

\author{
Jonathan K. Noel, Ziming Xuan \& Thomas F. Babor
}

To cite this article: Jonathan K. Noel, Ziming Xuan \& Thomas F. Babor (2017) Associations Between Thematic Content and Industry Self-Regulation Code Violations in Beer Advertising Broadcast During the U.S. NCAA Basketball Tournament, Substance Use \& Misuse, 52:8, 1076-1084, DOI: $10.1080 / 10826084.2016 .1271987$

To link to this article: https://doi.org/10.1080/10826084.2016.1271987

\section{Published online: 21 Mar 2017.}

Submit your article to this journal $\sqsubset$

Цll Article views: 61

View Crossmark data ¿

Citing articles: 3 View citing articles $\square$ 


\title{
Associations Between Thematic Content and Industry Self-Regulation Code Violations in Beer Advertising Broadcast During the U.S. NCAA Basketball Tournament
}

\author{
Jonathan K. Noel ${ }^{\mathrm{a}}$, Ziming Xuan ${ }^{\mathrm{b}}$, and Thomas F. Babor ${ }^{\mathrm{a}}$ \\ ${ }^{a}$ Community Medicine and Health Care, University of Connecticut School of Medicine, Farmington, Connecticut, USA; ${ }^{b}$ Community Health \\ Sciences, Boston University School of Public Health, Boston, Massachusetts, USA
}

\begin{abstract}
Background: Beer marketing in the United States is controlled through self-regulation, whereby the beer industry has created a marketing code and enforces its use. We performed a thematic content analysis on beer ads broadcast during a U.S. college athletic event and determined which themes are associated with violations of a self-regulated alcohol marketing code. Methods: 289 beer ads broadcast during the U.S. NCAA Men's and Women's 1999-2008 basketball tournaments were assessed for the presence of 23 thematic content areas. Associations between themes and violations of the U.S. Beer Institute's Marketing and Advertising Code were determined using generalized linear models. Results: Humor $(61.3 \%)$, taste $(61.0 \%)$, masculinity $(49.2 \%)$, and enjoyment $(36.5 \%)$ were the most prevalent content areas. Nine content areas (i.e., conformity, ethnicity, sensation seeking, sociability, romance, special occasions, text responsibility messages, tradition, and individuality) were positively associated with code violations ( $p<0.001-0.042$ ). There were significantly more content areas positively associated with code violations than content areas negatively associated with code violations $(p<$ 0.001). Conclusions: Several thematic content areas were positively associated with code violations. The results can inform existing efforts to revise self-regulated alcohol marketing codes to ensure better protection of vulnerable populations. The use of several themes is concerning in relation to adolescent alcohol use and health disparities.
\end{abstract}

\section{KEYWORDS}

Alcohol; marketing; advertising; self-regulation; adolescents
Alcohol use is responsible for 88,000 deaths, including approximately 4400 youth, and 2.5 million potential years old life lost in the United States (U.S.) each year (Centers for Disease Control and Prevention, n.d.; Stahre, Roeber, Kanny, Brewer, \& Zhang, 2014). The economic costs of excessive alcohol consumption amount to approximately $\$ 250$ billion annually (Sacks, Gonzales, Bouchery, Tomedi, \& Brewer, 2015). Youth are particularly vulnerable to alcohol-related consequences. Eleven percent of all alcohol in the United States is consumed by 12-20 year olds, primarily in the form of binge drinking (Office of Juvenile Justice and Delinquency Prevention, 2005), and there were 189,000 alcohol-attributable emergency room visits by youth in 2010 (Center for Behavioral Health Statistics and Quality, 2012). Early alcohol initiation is also associated with a greater probability of developing alcohol dependence or abuse later in life (Substance Abuse and Mental Health Services Administration, 2014). In 2013, 35\% of U.S. high school students drank alcohol in the past 30 days, and the past 30-day rate of heavy episodic (binge) drinking was approximately $21 \%$ (Kann et al., 2014).

Youth are regularly exposed to, and consistently demonstrate high awareness of, alcohol marketing. In the United States, 15-20 year olds reported seeing 2.79 magazine ads, hearing 1.59 radio ads, and seeing 2.48 billboards for distilled spirits per week (Fleming, Thorson, \& Atkin, 2004). Australian youth reported seeing up to 5.4 alcohol ads per week (Fielder, Donovan, \& Ouschan, 2009). In Brazil, $78.1 \%$ of teens reported seeing any alcohol ads in the past week (Pinsky et al., 2010), while 77\% of Scottish 12-14 year olds demonstrated awareness of alcohol advertising on television (Gordon, MacKintosh, \& Moodie, 2010). A high density of alcohol ads has been documented in public settings frequented by youth, including schools, churches, playgrounds, and public transportation (Gentry et al., 2011; Kwate, Jernigan, \& Lee, 2007; McKee, Jones-Webb, Hannan, \& Pham, 2011; Nyborn, Wukitsch, Nhean, \& Siegel, 2009). Awareness of online alcohol marketing activities is high among youth in several countries

CONTACT Jonathan K. Noel jknoel@hotmail.com @ University of Connecticut School of Medicine, Community Medicine and Health Care, 263 Farmington Avenue, MC 6325, Farmington, CT 06030-1912, USA. 
(Jones \& Magee, 2011; Lin, Caswell, You, \& Huckle, 2012), and the volume of alcohol marketing on social media platforms has been increasing over time (Winpenny, Marteau, \& Nolte, 2014) Moreover, per capita alcohol ad exposure may be increasing fastest among youth populations (Jernigan, Ostroff, \& Ross, 2005).

Alcohol ad exposure is linked to increased alcohol consumption. Twelve of thirteen studies analyzed in a review of the impact of alcohol marketing on youth concluded that marketing activities increased either alcohol initiation or alcohol consumption (Anderson, de Bruijn, Angus, Gordon, \& Hastings, 2009). The 13th study concluded that marketing activities increased intentions to drink. Using more stringent inclusion and exclusion criteria, a separate review of seven cohort studies found a modest association between alcohol advertising exposure and alcohol consumption in youth (Smith \& Foxcroft, 2009). Other studies have demonstrated that youth exposure to alcohol ads increases the risk for experiencing alcohol-related problems later in adolescence and that being able to name a favorite alcohol ad is a marker for binge drinking (Grenard, Dent, \& Stacy, 2013; Morgenstern et al., 2014). Moreover, a modeling study found that a $28 \%$ reduction in alcohol advertising was associated with reductions of $16 \%$ and $33 \%$ in youth drinking and youth binge drinking, respectively (Saffer \& Dave, 2006).

To protect youth and other vulnerable populations from the effects of alcohol marketing, the alcohol industry has promoted self-regulated marketing and advertising codes as a method to restrict exposure to harmful content (International Center for Alcohol Policies, 2011). Published by the International Alliance for Responsible Drinking (IARD), an alcohol industry funded organization formerly known as the International Center for Alcohol Policies, the Guiding Principles: Self-Regulation of Marketing Communications for Beverage Alcohol (Guiding Principles) was designed to cover all alcoholic products and marketing in all media. The Guiding Principles prohibit alcohol marketing to be placed in any media where the audience composition is less than $70 \%$ above the legal purchase age and contain several guidelines restricting advertising content, grouped within the following categories: responsible marketing communications, responsible consumption, health and safety, minors, and the effects of alcohol. Key guidelines include prohibitions on the use of content that can be appealing to minors and content addressed at vulnerable groups, such as pregnant women and children. In the United States, alcohol marketing self-regulation is largely product specific. Principally beer, wine, and distilled spirits producers follow marketing codes published by the U.S. Beer Institute (2011), the Wine Institute (2011), and the Distilled Spirits
Council of the United States (2011). The guidelines contained within these codes are similar to IARD's Guiding Principles.

Systematic evaluations of both the exposure and content guidelines of self-regulated alcohol marketing codes have shown them to be ineffective. In the 25 largest U.S. markets in 2010, 23.7\% of alcohol ads and 33\% of alcohol ad impressions on television occurred during programming with audiences consisting of greater than $30 \%$ youth (Jernigan, Ross, Ostroff, McKnight-Eily, \& Brewer, 2013). Between 2005 and 2012, there were 15.2 billion alcohol ad impressions on television that were noncompliant with existing alcohol marketing self-regulated codes (Ross, Brewer, \& Jernigan, 2016). In 2011, magazine ads for eleven of the alcohol brands most consumed by youth generated more ad exposure for males 18-20 years old than all other age groups (Ross et al., 2014). For females 18-20 years old, 16 of the alcohol brands most consumed by youth generated more ad exposure than all other age groups. Moreover, up to $74 \%$ of unique alcohol ads broadcast on U.S. television may contain violations of the content guidelines of the codes, depending on code version and scoring algorithm used (Babor, Xuan, Damon, \& Noel, 2013). Similar violation rates have been reported for digital content produced by U.K. alcohol brands (Gordon, 2011b).

Several content analyses of alcohol ads without regard to a marketing code have been conducted, although relatively few have been performed on television ads. In U.S. television ads, themes of camaraderie, relaxation, and humor predominated in the early 1980s (Finn \& Strickland, 1982). The use of these themes continued into the early 2000s, with the addition of masculinity and sex appeal, particularly when female characters were shown (Austin \& Hust, 2005). The use of youthoriented content, such as cartoons and animals, has also been documented (Pasch, Komro, Perry, Hearst, \& Farbakhsh, 2009).

Few content analyses of alcohol ads broadcast on television have been performed. Furthermore, despite a number of studies identifying thematic content used in alcohol ads and other studies determining rates of violations of the alcohol industry's self-regulated marketing code, no study has systematically associated alcohol ad content with code violations. That is, no study has determined which content used in alcohol advertising may be potentially harmful based on its association with violations of a marketing code. Since marketing codes are designed to protect vulnerable groups, content that violates a marketing code may be particularly harmful to these populations. We performed a thematic content analysis on a set of advertisements that were previously rated for code violations. Associations between thematic content and 
code violations were determined using generalized linear models.

\section{Methods}

\section{Ad selection}

In a previous study, all unique beer ads $(N=289)$ broadcast during the 1999-2008 men's and women's NCAA basketball tournament were rated for violations of the U.S. Beer Institute Code (Babor et al., 2013). All of these advertisements were included in this study.

\section{Ad characterization}

For each ad, the year of broadcast, alcohol producer (Anheuser-Busch, SABMiller, Other), type of game (Men's, Women's, or either Men's or Women's games) and the type of beer (Light, Regular, or Flavored Malt Beverages) was recorded. An "Other" category was created for a diverse group of smaller alcohol producers other than Anheuser-Busch and SABMiller. For game type, the "either Men's or Women's game" category was created because individual broadcasts of the same ad could have occurred in either a Men's game or a Women's game, but such distinctions are lost when aggregating by the total number of times broadcast.

\section{Code violations}

Code violation ratings were based on the 2006 U.S. Beer Institute Marketing and Advertising code. These ratings have been previously published and the results from the previous study have been carried over to the current analysis (Babor et al., 2013). Briefly, the ads were rated for violations using the Delphi technique, which is a procedure involving multiple rounds of rating to build group consensus (Hasson, Keeney, \& McKenna, 2000), and using a questionnaire specifically designed to detect violations in a self-regulated alcohol marketing code (Babor, Xuan, \& Proctor, 2008). The questionnaire contained three types of questions. First, five-point Likert scale questions were used to assess the participant's level of agreement with a statement of fact or opinion (e.g., "This ad depicts the image of Santa Claus"). The response categories ranged from strongly disagree to strongly agree. Second, participants were asked to determine the apparent age of the main character of the ad (e.g., "How old do you think this actor is?") or which age group the ad would primarily appeal to (e.g., "The images in this ad are most appeal to which of the following age groups: below 21; between 21 and 30; between 31 and 40; between 41 and 50; above 50?"). Third, participants were asked to assess how much alcohol consumption was taking place in the situation shown in the ad (e.g., "How many drinks do you estimate this person is likely to consume in the situation shown in the ad?").

Although several algorithms used to calculate violations were tested in the previous study, a violation in the present study was defined using the frequency criterion, which used an aggregate scoring algorithm that required a majority of 15 expert raters to rate the advertisement in violation of a guideline (Babor et al., 2013). For example, a violation would occur if more than $50 \%$ of the experts agreed or strongly agreed "This ad depicts situations where beer is being consumed excessively." This criterion is a conservative approach to defining code violations that still prevents any single rating from influencing the final determination of a violation. The "experts" who rated the ads were public health professionals who had experience or expertise in public health, mental health, communications, alcoholism treatment, or substance abuse research.

\section{Content ratings}

A separate procedure was used to identify thematic content in the ads. Each ad was rated for the presence of 27 preliminary thematic content areas. Of these, 26 were previously described by others (Austin \& Hust, 2005; Finn \& Strickland, 1982; Pasch et al., 2009; Pinsky \& Silva, 1999). A 27th category was formed when responsibility messages were subdivided into text or spoken messages. Due to overlapping definitions used in previous studies, several categories were collapsed or eliminated. Three categories (health benefit, carbs, and calories) were collapsed into a "Health" category. The categories of violence and action/adventure were collapsed into a "Sensation Seeking" category. Thus, the following 23 content areas were investigated: animals, conformity, enjoyment, ethnicity, happiness, health, humor, individuality, irony, masculinity, quality, relaxation, religion, responsibility messages: spoken, responsibility messages: text, romance, self-reward, sensation seeking, sex, special occasion, sociability, taste, and tradition.

Three raters who had experience conducting public health, substance use, and marketing research were recruited to rate the ads for content. All three rated the first 50 ads, with substantial to perfect item-level interrater reliability (ICCs $=0.703-1.00$ ). For the remaining 239 ads, 191 were rated by raters 1 and 2 , and 48 were rated by raters 1 and 3 . Item-level interrater reliability between raters 1 and 2 (ICCs $=0.798-1.00)$ and between raters 1 and 3 (ICCs $=0.701-1.00$ ) was also substantial to perfect. Ads were rated separately and responses were recorded on paper worksheets. For ads that were rated by two raters, the presence of a content area was defined as both raters 
agreeing the content area was present, and the absence of a content area was defined as when at least one rater determined the content area was not present. For ads that were rated by three raters, the presence of a content area was defined as when two or more raters agreed the content area was present, and the absence of a content area was defined as when two or more raters agreed the content area was not present.

\section{Statistical analysis}

To determine which content areas were associated with code violations, generalized linear models with a Poisson distribution and a Log link function were used with an iterative, backward selection process. The total number of violations per ad was specified as the dependent variable. All content areas were included in the model during the first iteration except for religion, sex, and humor. Religion and sex were excluded because by definition each is a violation of the U.S. Beer Institute Code. Humor was excluded because by definition it is not a violation. Nonsignificant content areas were removed and the process repeated until a stable model was produced. Since a single ad can contain multiple content areas simultaneously, content areas positively associated with code violations (CAPs) and content areas negatively associated with code violations (CANs) were collapsed into two continuous variables. The total number of CAPs versus CANs per broadcast was compared using a paired $t$ test.

Statistical analysis was performed using SPSS Version 22.0 (Armonk, NY: IBM Corp.). All analyses were weighted by the number of times an ad was broadcast unless otherwise noted. Statistical significance was set at 0.05 a priori. This study was approved by the Institutional Review Board within the University of Connecticut Health Center Human Subjects Protection Office.

\section{Results}

There were 1747 broadcasts of the 289 ads included in the study (Table 1). Taste occurred in the majority of broadcasts and ads (61.0\% and 57.8\%) while humor occurred in a majority of all broadcasts (61.3\%). Masculinity (49.2\% and $44.3 \%)$ and enjoyment (36.5\% and $34.6 \%$ ) occurred in over one-third of all broadcasts and ads, respectively. Irony was absent from all broadcasts. Text responsibility messages (e.g., "Drink Responsibly") were present in $21.5 \%$ of ads and $25.2 \%$ of broadcasts. Spoken responsibility messages were present in only $3.1 \%$ of ads and $2.2 \%$ of broadcasts. The code violation rate was $63.9 \%$ among the broadcasts and $61.6 \%$ among the ads (Table 2).

Broadcasts were distributed evenly between study years, with each contributing between $7.3 \%$ and $12.9 \%$ of
Table 1. Frequency of thematic content areas.

\begin{tabular}{|c|c|c|}
\hline Content area & $\begin{array}{l}\text { Number of times } \\
\text { broadcast (\%) }\end{array}$ & $\begin{array}{l}\text { Number of unique ads } \\
(\%)\end{array}$ \\
\hline Humor & $1071(61.3)$ & $144(49.8)$ \\
\hline Taste & $1066(61.0)$ & $167(57.8)$ \\
\hline Masculinity & 859 (49.2) & $128(44.3)$ \\
\hline Enjoyment & $637(36.5)$ & $100(34.6)$ \\
\hline Sociability & $481(27.5)$ & $82(28.4)$ \\
\hline $\begin{array}{l}\text { Responsibility } \\
\text { message: Text }\end{array}$ & $441(25.2)$ & $62(21.5)$ \\
\hline Sensation seeking & $420(24.0)$ & $69(23.9)$ \\
\hline Romance & $404(23.1)$ & $59(20.4)$ \\
\hline Individuality & 378 (21.6) & $69(23.9)$ \\
\hline Sex & $322(18.4)$ & $52(18.0)$ \\
\hline Health & $228(13.1)$ & $37(12.8)$ \\
\hline Special occasion & $211(12.1)$ & $38(13.1)$ \\
\hline Self-reward & 199 (11.4) & $26(9.0)$ \\
\hline Tradition & $187(10.7)$ & $40(13.8)$ \\
\hline Animals & $172(9.8)$ & $28(9.7)$ \\
\hline Ethnicity & $145(8.3)$ & $21(7.3)$ \\
\hline Quality & $109(6.2)$ & $28(9.7)$ \\
\hline Happiness & $105(6.0)$ & $23(8.0)$ \\
\hline Relaxation & $83(4.8)$ & $20(6.9)$ \\
\hline $\begin{array}{l}\text { Responsibility } \\
\text { message: Spoken }\end{array}$ & $39(2.2)$ & $9(3.1)$ \\
\hline Conformity & $28(1.6)$ & $7(2.4)$ \\
\hline Religion & $7(0.4)$ & $1(0.3)$ \\
\hline Irony & $0(0.0)$ & $0(0.0)$ \\
\hline Total & $1747(100)$ & $289(100)$ \\
\hline
\end{tabular}

broadcasts (Table 2). Approximately $60 \%$ of all broadcasts and ads were produced by Anheuser-Busch. Most broadcasts were for light beer (62.6\%) and only broadcast during Men's games (63.3\%).

Two iterations were required before a stable model associating thematic content areas with code violations was produced. Nine content areas were identified as

Table 2. Ad and broadcast characteristics.

\begin{tabular}{|c|c|c|}
\hline Variable & Broadcasts & Ads \\
\hline CAP per broadcast* & $1.54(1.20)$ & $1.55(1.22)$ \\
\hline CAN per broadcast* & $0.69(0.73)$ & $0.69(0.73)$ \\
\hline Code violations** & $1117(63.9)$ & 178 (61.6) \\
\hline \multicolumn{3}{|l|}{ Year of broadcast** } \\
\hline 1999 & $144(8.2)$ & $27(9.3)$ \\
\hline 2000 & $127(7.3)$ & $28(9.7)$ \\
\hline 2001 & $151(8.6)$ & $31(10.7)$ \\
\hline 2002 & $193(11.0)$ & $36(12.5)$ \\
\hline 2003 & $189(10.8)$ & $35(12.1)$ \\
\hline 2004 & $200(11.4)$ & $28(9.7)$ \\
\hline 2005 & $191(10.9)$ & $32(11.1)$ \\
\hline 2006 & $161(9.2)$ & $27(9.3)$ \\
\hline 2007 & $166(9.5)$ & $20(6.9)$ \\
\hline 2008 & 225 (12.9) & $25(8.7)$ \\
\hline \multicolumn{3}{|l|}{ Producer** } \\
\hline Anheuser-Busch & $1010(57.8)$ & $180(62.3)$ \\
\hline SABMiller & $481(27.5)$ & $70(24.2)$ \\
\hline Other & $256(14.7)$ & $39(13.5)$ \\
\hline \multicolumn{3}{|l|}{ Beer type ${ }^{* *}$} \\
\hline Light & $1093(62.6)$ & $184(63.7)$ \\
\hline Regular & $516(29.5)$ & 89 (30.8) \\
\hline Flavored malt beverages & $138(7.9)$ & $16(5.5)$ \\
\hline \multicolumn{3}{|l|}{ Game type** } \\
\hline Men's only & $1105(63.3)$ & $170(58.8)$ \\
\hline Either men's or women's & $343(19.6)$ & $59(20.4)$ \\
\hline Women's only & $299(17.1)$ & $60(20.8)$ \\
\hline
\end{tabular}

*Mean (SD); ** Number (\%). 
Table 3. Content areas significantly associated with code violations.

\begin{tabular}{|c|c|c|c|c|}
\hline Content area & $\beta$ & $95 \% \mathrm{Cl}$ & Wald $\chi^{2}$ & $p$ \\
\hline \multicolumn{5}{|l|}{ CAPs } \\
\hline Conformity & 0.51 & $0.28,0.74$ & 18.26 & $<0.001$ \\
\hline Ethnicity & 0.39 & $0.25,0.54$ & 29.76 & $<0.001$ \\
\hline Sensation seeking & 0.33 & $0.24,0.42$ & 51.44 & $<0.001$ \\
\hline Sociability & 0.32 & $0.24,0.40$ & 56.75 & $<0.001$ \\
\hline Romance & 0.30 & $0.21,0.39$ & 44.36 & $<0.001$ \\
\hline Special occasion & 0.28 & $0.19,0.38$ & 37.70 & $<0.001$ \\
\hline Responsibility Message: Text & 0.23 & $0.13,0.33$ & 21.51 & $<0.001$ \\
\hline Tradition & 0.14 & $0.01,0.27$ & 4.14 & 0.042 \\
\hline Individuality & 0.11 & $0.03,0.20$ & 6.84 & 0.009 \\
\hline \multicolumn{5}{|l|}{ CANs } \\
\hline Quality & -2.35 & $-2.91,-1.79$ & 68.59 & $<0.001$ \\
\hline Self-reward & -0.61 & $-0.76,-0.47$ & 71.17 & $<0.001$ \\
\hline Responsibility message: Spoken & -0.45 & $-0.76,-0.13$ & 7.77 & 0.005 \\
\hline Health & -0.25 & $-0.38,-0.11$ & 13.13 & $<0.001$ \\
\hline Enjoyment & -0.09 & $-0.18,-0.01$ & 5.12 & 0.24 \\
\hline
\end{tabular}

CAPs, and five content areas were identified as CANs (Table 3). CAPs were associated with an approximate 0.1 to 0.5 increase in violations per broadcast. There was greater variability in the coefficients for CANs. Interestingly, text responsibility messages $(\beta(95 \% \mathrm{CI})=0.23$ $(0.13,0.33), p<0.001)$ were identified as a CAP while spoken responsibility messages $(\beta(95 \% \mathrm{CI})=-0.45$ $(-0.76,-0.13), \mathrm{p}=0.005)$ were identified as a CAN. There were significantly more CAPs (mean $(\mathrm{SD})=1.54$ (1.20)) than CANs (mean $(\mathrm{SD})=0.69(0.73))$ per broadcast $(\mathrm{t}(1746)=28.354, p<0.001$; Table 2$)$.

\section{Discussion}

Thematic content used in beer ads is both positively and negatively associated with violations of the U.S. Beer Institute's self-regulated marketing and advertising code. Themes positively associated with code violations (i.e. conformity, ethnicity, sensation seeking, sociability, romance, special occasions, text responsibility messages, tradition, and individuality) may be considered potentially harmful to vulnerable populations.

Reducing the number of CAPs used in beer advertisements while promoting the use of CANs may reduce the number of ads that violate existing self-regulated alcohol marketing codes and potentially better protect populations that may be vulnerable to beer marketing. Several public health researchers have called for changes in alcohol marketing codes, particularly where self-regulation dominates (Babor et al., 2010; Gordon, 2011a; Hastings \& Sheron, 2013), and these results can inform such efforts. However, achieving such changes may be difficult. While self-regulation has worked in other industries, these regulations were required to ensure economic viability of the industry (Sharma, Teret, \& Brownell, 2010). The alcohol industry is unlikely to have a similar opinion on regulations that restrict their ability to reach existing and new customers.
If pledges by the alcohol industry to protect vulnerable populations are followed, these findings can inform changes in self-regulated alcohol marketing codes. The existing structure of these regulations is restrictive, listing specific types of content that are barred from appearing in alcohol advertising. The thematic content areas identified here as being associated with code violations could be added to these codes and explicitly banned from being used in future alcohol marketing campaigns. Ideally, existing voluntary or statutory alcohol marketing codes would use a permissible structure similar to the Loi Évin (1991) in France, which states only the content that is allowed. These findings suggest that permissible codes should focus principally on product quality.

The findings also suggest that if responsibility messages are included in alcohol advertising broadcast on television, spoken responsibility messages should be used in place of text messages. Adolescent viewers may not notice text responsibility messages (e.g., "Drink Responsibly," "Live Responsibly," and "Enjoy Responsibly"). In an eye-tracking study of magazine alcohol ads, adolescents spent only $0.35 \mathrm{~s}$ fixated on the responsibility message (Thomsen \& Fulton, 2007). Moreover, text responsibility messages are unlikely to define the meaning of responsible drinking or promote abstinence as an acceptable alternative to drinking (Smith et al., 2014). Instead, by combining persuasion techniques with nondescript catchphrases, these ostensible prevention messages are, according to some critics, no more than a marketing tactic designed to assuage critics of the alcohol industry (Barry \& Goodson, 2010).

The use of several content areas that were associated with code violations is inconsistent with the intent of selfregulated codes to protect vulnerable populations. The desire for larger friend networks (i.e., sociability) and conforming to peer and adult alcohol norms (i.e., conformity) are strong predictors of adolescent alcohol use. Results 
from the Add Health Study indicate that alcohol consumption leads to an increase in popularity among adolescents (Ali, Amialchuk, \& Nikaj, 2014), and the desire for larger and stronger friend networks on social media is positively associated with alcohol use (Cook, Bauermeister, Gordon-Messer, \& Zimmerman, 2013; Huang, Soto, Fujimoto, \& Valente, 2014). Among disadvantaged youth that were marginalized by peers, alcohol use was seen as an acceptable, alternative activity to bond with other marginalized youth (Fletcher \& Bonell, 2013). Furthermore, while acceptance as a member of a peer group is important for the development of healthy social skills, it may require an individual to concede to group norms (Santor, Messervey, \& Kusumakar, 2000). This strong pressure to conform can result in earlier alcohol initiation and greater alcohol consumption (Santor, Messervey, \& Kusumakar, 2000; Trucco, Colder, Bowker, \& Wieczorek, 2011).

Alcohol advertising that focuses on ethnicity may be addressing populations that suffer from significant alcohol-related health disparities. Hispanic drinkers who consume low levels of alcohol report greater alcohol dependence symptoms and alcohol-related social consequences compared to Caucasian drinkers with similar drinking patterns (Mulia, Ye, Zemore, \& Greenfield, 2008). Hispanic drinkers are at a greater risk for developing liver disease and have the highest mortality rate due to liver cirrhosis (Flores et al. 2008; Stinson, Grant, \& Dufour, 2001; Yoon \& Yi 2008), while being less likely to receive specialty alcohol treatment (Schmidt, Ye, Greenfield, \& Bond. 2007). Hispanic populations also have higher rates of alcohol-attributable intimate partner violence than Caucasian populations (Caetano, Cunradi, Clark, \& Schafer, 2000).

Humor was the most prevalent content area but is explicitly excluded as a violation of the U.S. Beer Institute's marketing code. Eisend (2011) has suggested that humor in advertising creates a distraction from counterarguments, thereby reducing negative cognitions associated with a brand. Humor has been used extensively to mask deceptive marketing practices (Shabbir \& Thwaites, 2007), and ads may be significantly more memorable when humor is used (Cline \& Kellaris, 2007; Eisend, 2009).

\section{Limitations}

There are a number of limitations to this study. First, the ads may not be representative of all beer ads produced throughout a calendar year. However, because the ads were broadcast during a popular sporting event and were collected over several years, they are likely representative of beer ads broadcast during large U.S. sporting events, where a majority of alcohol advertising may be located and where a significant proportion of the viewers is likely to be under the U.S. legal alcohol purchase age of 21 years (Lyons McNeill, \& Britton, 2014; O’Brien et al., 2015; Zwarun, 2006). Second, we were unable to estimate exposure to these advertisements. It is possible that ads with CANs were viewed by more individuals than ads with CAPs, although we believe that to be unlikely. Third, the thematic content analysis performed did not include all possible themes present in alcohol ads, instead focusing specifically on those themes that have been identified in prior research. There are likely several additional thematic content areas that can influence code violation rates, such as a party atmosphere or volume of alcoholic drinks consumed. Alternatively, excluded non-thematic ad characteristics, such as colors used or lighting levels, may also influence code violation rates (Hutchison, Thomas, \& Elias, 2011; Wauters, Brengman, \& Mahama, 2014).

\section{Conclusions}

Several thematic content areas used in beer advertising were positively associated with violations of the industry's self-regulated marketing and advertising code. These findings can inform efforts to revise existing alcohol marketing codes. Themes positively associated with code violations can be expressly banned in restrictive codes, and themes negatively associated with code violations can be expressly allowed in permissible codes. The use of several themes is concerning in relation to adolescent alcohol use and health disparities.

\section{Acknowledgment}

Donna Damon assisted in the thematic coding of the alcohol advertisements.

\section{Declaration of interest}

The authors report no conflicts of interest.

\section{Funding}

This study was funded by the National Institute on Alcohol Abuse and Alcoholism (grant 1R01AA015383) and a University of Connecticut Graduate Program Award for PhD Students in Public Health.

\section{References}

Ali, M. M., Amialchuk, A., \& Nikaj, S. (2014). Alcohol consumption and social network ties among adolescents: Evidence from Add Health. Addictive Behaviors, 39(5), 918-922. 
Anderson, P., de Bruijn, A., Angus, K., Gordon, R., \& Hastings, G. (2009). Impact of alcohol advertising and media exposure on adolescent alcohol use: A systematic review of longitudinal studies. Alcohol and Alcoholism, 44(3), 229-243.

Austin, E. W. \& Hust, S. J. (2005). Targeting adolescents? The content and frequency of alcoholic and nonalcoholic beverage ads in magazine and video formats November 1999April 2000. Journal of Health Communication, 10(8), 769785.

Babor, T., Caetano, R., Casswell, S., Edwards, G., Giesbrecht, N., Graham, K., Rossow, I. (2010). Alcohol: No ordinary commodity (2nd ed.). New York, NY: Oxford.

Babor, T. F., Xuan, Z., Damon, D., \& Noel, J. (2013). An empirical evaluation of the US Beer Institute's self-regulation code governing the content of beer advertising. American Journal of Public Health, 103(10), e45-e51.

Babor, T. F., Xuan, Z., \& Proctor, D. (2008). Reliability of a rating procedure to monitor industry self-regulation codes governing alcohol advertising content. Journal of Studies on Alcohol and Drugs, 69(2), 648-657.

Barry, A. E., \& Goodson, P. (2010). Use (and misuse) of the responsible drinking message in public health and alcohol advertising: a review. Health Education \& Behavior, 37(2), 288-303.

Caetano, R., Cunradi, C. B., Clark, C. L., \& Schafer, J. (2000). Intimate partner violence and drinking patterns among white, black, and Hispanic couples in the U.S. Journal of Substance Abuse, 11(2), 123-138.

Center for Behavioral Health Statistics and Quality. (2012). The DAWN Report: Highlights of the 2010 drug Abuse Warning Network (DAWN) findings on drug-related emergency department visits. Rockville, MD: Substance Abuse and Mental Health Services Administration. Retrieved from http://archive.samhsa.gov/data/2k12/DAWN096/SR096ED Highlights2010.pdf

Centers for Disease Control and Prevention. (n.d.). Alcohol-Related Disease Impact (ARDI). Retrieved from http://nccd.cdc.gov/DPH_ARDI/default/default.aspx

Cline, T. W. \& Kellaris, J. J. (2007). The influence of humor strength and humor-relatedness on ad memorability: A dual process model. Journal of Advertising, 36(1), 55-67.

Cook, S. H., Bauermeister, J. A., Gordon-Messer, D., \& Zimmerman, M. A. (2013). Online network influences on emerging adults' alcohol and drug use. Journal of Youth and Adolescence, 42(11), 1674-1686.

Distilled Spirits Council of the United States. (2011). Code of responsible practices for beverage alcohol advertising and marketing. Retrieved from http://www. discus.org/assets/1/7/May_26_2011_DISCUS_Code_ Word_Version1.pdf

Eisend, M. (2009). A meta-analysis of humor in advertising. Journal of the Academy of Marketing Science, 37(2), 191-203.

Eisend, M. (2011). How humor in advertising works: A metaanalytic test of alternative models. Marketing Letters, 22(2), $115-132$.

Fielder, L., Donovan, R. J., \& Ouschan, R. (2009). Exposure of children and adolescents to alcohol advertising on Australian metropolitan free-to-air television. Addiction, 104(7), 1157-1165.

Finn, T. A. \& Strickland, D. E. (1982). A content analysis of beverage alcohol advertising. II. Television advertising. Journal of Studies on Alcohol, 43(9), 964-989.
Fleming, K., Thorson, E., \& Atkin, C. K. (2004). Alcohol advertising exposure and perceptions: links with alcohol expectancies and intentions to drink or drinking in underaged youth and young adults. Journal of Health Communication, 9(1), 3-29.

Fletcher, A., \& Bonell, C. (2013). Social network influences on smoking, drinking and drug use in secondary school: Centrifugal and centripetal forces. Sociology of Health \& Illness, 35(5), 699-715.

Flores, Y. N., Yee, H. F., Jr., Leng, M., Escarce, J. J., Bastani, R., Salmerón, J., \& Morales, L. S. (2008). Risk factors for chronic liver disease in Blacks, Mexican Americans, and Whites in the United States: Results from NHANES IV, 1999-2004. American Journal of Gastroenterology, 103(9), 2231-2238.

Gentry, E., Poirier, K., Wilkinson, T., Nhean, S., Nyborn, J., \& Siegel, M. (2011). Alcohol advertising at Boston subway stations: An assessment of exposure by race and socioeconomic status. American Journal of Public Health, 101(10), 1936-1941.

Gordon, R. (2011a). Alcohol marketing and youth drinking: A rejoinder to the alcohol industry. Alcohol and Alcoholism, 46(4), 369-370.

Gordon, R. (2011b). An audit of alcohol brand websites. Drug and Alcohol Review, 30(6), 638-644.

Gordon, R., MacKintosh, A. M., \& Moodie, C. (2010). The impact of alcohol marketing on youth drinking behaviour: A two-stage cohort study. Alcohol and Alcoholism, 45(5), $470-480$

Grenard, J. L., Dent, C. W., \& Stacy, A. W. (2013). Exposure to alcohol advertisements and teenage alcohol-related problems. Pediatrics, 131(2), e369-e379.

Hasson, F., Keeney, S., \& McKenna, H. (2000). Research guidelines for the Delphi survey technique. Journal of Advanced Nursing, 32(4), 1008-1015.

Hastings, G., \& Sheron, N. (2013). Alcohol marketing: grooming the next generation: Children are more exposed than adults and need much stronger protection. BMJ, 346, f1227.

Huang, G. C., Soto, D., Fujimoto, K., \& Valente, T. W. (2014). The interplay of friendship networks and social networking sites: Longitudinal analysis of selection and influence effects on adolescent smoking and alcohol use. American Journal of Public Health, 104(8), e51-e59.

Hutchison, J., Thomas, N. A., \& Elias, L. (2011). Leftward lighting in advertisements increases advertisement ratings and purchase intention. Laterality, 16(4), 423-432.

International Center for Alcohol Policies. (2011). Guiding principles: Self-regulation of marketing communications for beverage alcohol. Washington, DC. Retrieved February 12, 2016 from http://www.icap.org/ LinkClick.aspx?fileticket $=y$ RzKnnECzO0\%3d\&tabid $=105$

Jernigan, D. H., Ostroff, J., \& Ross, C. (2005). Alcohol advertising and youth: A measured approach. Journal of Public Health Policy, 26(3), 312-325.

Jernigan, D. H., Ross, C. S., Ostroff, J., McKnight-Eily, L. R., \& Brewer, R. D. (2013). Youth exposure to alcohol advertising on television-25 markets, United States, 2010. Morbidity and Mortality Weekly Report, 62(44), 877-880.

Jones, S. C., \& Magee, C. A. (2011). Exposure to alcohol advertising and alcohol consumption among Australian adolescents. Alcohol and Alcoholism, 46, 630-637.

Kann, L., Kinchen, S., Shanklin, S. L., Flint, K. H., Kawkins, J., Harris, W. A., Centers for Disease Control and Prevention 
(CDC). (2014). Youth risk behavior surveillance-United States, 2013. Morbidity and Mortality Weekly Report Surveillance Summaries, 63(Suppl 4).

Kwate, N. O., Jernigan, M., \& Lee, T. (2007). Prevalence, proximity and predictors of alcohol ads in Central Harlem. Alcohol and Alcoholism, 42(6), 635-640.

Lin, E. Y., Caswell, S., You, R. Q., \& Huckle, T. (2012). Engagement with alcohol marketing and early brand allegiance in relation to early years of drinking. Addiction Research and Theory, 20, 329-338.

Loi Évin. (1991, January 10). Loi relative à la lutte contre le tabagisme et l'alcoolisme (Pub. L. No. 91-32). Paris, France: Parlement Français.

Lyons, A., McNeill, A., \& Britton, J. (2014). Alcohol imagery on popularly viewed television in the UK. Journal of Public Health, 36(3), 426-434.

McKee, P., Jones-Webb, R., Hannan, P., \& Pham, L. (2011). Malt liquor marketing in inner cities: The role of neighborhood racial composition. Journal of Ethnicity in Substance Abuse, 10(1), 24-38.

Morgenstern, M., Sargent, J. D., Sweeting, H., Faggiano, F., Mathis, F., \& Hanewinkel, R. (2014). Favourite alcohol advertisements and binge drinking among adolescents: A cross-cultural cohort study. Addiction, 109(12), 2005-2015.

Mulia, N., Ye, Y., Zemore, S. E., \& Greenfield, T. K. (2008). Social disadvantage, stress, and alcohol use among Black, Hispanic, and White Americans: Findings from the 2005 U.S. National Alcohol Survey. Journal of Studies on Alcohol and Drugs, 69(6), 824-833.

Nyborn, J. A., Wukitsch, K., Nhean, S., \& Siegel, M. (2009). Alcohol advertising on Boston's Massachusetts Bay Transportation Authority transit system: An assessment of youths' and adults' exposure. American Journal of Public Health, 99(Suppl 3), S644-S648.

O’Brien, K. S., Carr, S., Ferris, J., Room, R., Miller, P., Livingston, M., Lynott, D. (2015). Alcohol advertising in sport and nonsport TV in Australia, during children's viewing times. PLoS One, 10(8), e0134889.

Office of Juvenile Justice and Delinquency Prevention. (2005). Drinking in America: Myths, realities, and prevention policy. Retrieved from http://www.lhc.ca. gov/lhc/drug/DrinkinginAmericaMosherSep26.pdf

Pasch, K. E., Komro, K. A., Perry, C. L., Hearst, M. O., \& Farbakhsh, K. (2009). Does outdoor alcohol advertising around elementary schools vary by the ethnicity of students in the school? Ethnicity \& Health, 14(2), 225-236.

Pinsky, I., El Jundi, S. A. R. J., Sanches, M., Zaleski, M. J. B., Laranjeira, R. R., \& Caetano R. (2010). Exposure of adolescents and young adults to alcohol advertising in Brazil. Journal of Public Affairs, 10(1-2), 50-58.

Pinsky, I., \& Silva, M. T. (1999). A frequency and content analysis of alcohol advertising on Brazilian television. Journal of Studies on Alcohol, 60(3), 394-399.

Ross, C. S., Brewer, R. D., \& Jernigan, D. H. (2016). The potential impact of a "No-Buy" list on youth exposure to alcohol advertising on cable television. Journal of Studies on Alcohol and Drugs, 77, 7-16.

Ross, C. S., Ostroff, J., Siegel, M. B., DeJong, W., Naimi, T. S., \& Jernigan, D. H. (2014). Youth alcohol brand consumption and exposure to brand advertising in magazines. Journal of Studies on Alcohol and Drugs, 75, 615-622.
Sacks, J. J., Gonzales, K. R., Bouchery, E. E., Tomedi, L. E., \& Brewer, R. D. (2015). 2010 national and state costs of excessive alcohol consumption. American Journal of Preventive Medicine, 49(5), e73-e79.

Saffer, H., \& Dave, D. (2006). Alcohol advertising and alcohol consumption by adolescents. Health Economics, 15(6), 617637.

Santor, D. A., Messervey, D., \& Kusumakar, V. (2000). Measuring peer pressure, popularity, and conformity in adolescent boys and girls: Predicting school performance, sexual attitudes and substance abuse. Journal of Youth and Adolescence, 29, 163-182.

Schmidt, L. A., Ye, Y., Greenfield, T. K., \& Bond, J. (2007). Ethnic disparities in clinical severity and services for alcohol problems: Results from the National Alcohol Survey. Alcoholism: Clinical and Experimental Research, 31(1), 48-56.

Shabbir, H. \& Thwaites, D. (2007). The use of humor to mask deceptive advertising: It's no laughing matter. Journal of Advertising, 36(2), 75-85.

Sharma, L. L., Teret, S. P., \& Brownell, K. D. (2010). The food industry and self-regulation: Standards to promote success and to avoid public health failures. American Journal of Public Health, 100(2), 240-246.

Smith, K. C., Cukier, S., \& Jernigan, D. H. (2014). Defining strategies for promoting product through 'drink responsibly' messages in magazine ads for beer, spirits and alcopops. Drug and Alcohol Dependence, 142, 168-173.

Smith, L. A., \& Foxcroft, D. R. (2009). The effect of alcohol advertising, marketing and portrayal on drinking behavior in young people: Systematic review of prospective cohort studies. BMC Public Health, 9, 51.

Stahre, M., Roeber, J., Kanny, D., Brewer, R. D., \& Zhang, X. (2014). Contribution of excessive alcohol consumption to deaths and years of potential life lost in the United States. Preventing Chronic Disease, 11, 130293.

Stinson, F. S., Grant, B. F., \& Dufour, M. C. (2001). The critical dimension of ethnicity in liver cirrhosis mortality statistics. Alcoholism: Clinical and Experimental Research, 25(8), 1181-1187.

Substance Abuse and Mental Health Services Administration. (2014). Results from the 2013 National Survey on Drug Use and Health: Summary of national findings. NSDUH Series H-48, HHS Publication No. (SMA) 14-4863. Retrieved rom http://www.samhsa.gov/data/sites/default/files/NSDUHres ultsPDFWHTML2013/Web/NSDUHresults2013.pdf

Thomsen, S. R., \& Fulton, K. (2007). Adolescents' attention to responsibility messages in magazine alcohol advertisements: An eye-tracking approach. Journal of Adolescent Health, 41(1), 27-34.

Trucco, E. M., Colder, C. R., Bowker, J. C., \& Wieczorek, W. F. (2011). Interpersonal goals and susceptibility to peer influence: Risk factors for intentions to initiate substance use during early adolescence. Journal of Early Adolescence, 31(4), 526-547.

U.S. Beer Institute. (2015). Beer Institute advertising and marketing code. Retrieved from http://www.beerinstitute. org/assets/uploads/general-upload/2015-Beer-Ad-CodeBrochure.pdf

Wauters, B., Brengman, M., \& Mahama, F. (2014). The impact of pleasure-evoking colors on the effectiveness of threat (fear) appeals. Psychology and Marketing, 31(12), 1051-1063. 
Wine Institute. (2011). Code of advertising standards. Retrieved from http://www.wineinstitute.org/initiatives/ issuesandpolicy/adcode/details

Winpenny, E. M., Marteau, T. M., \& Nolte, E. (2014). Exposure of children and adolescents to alcohol marketing on social media websites. Alcohol and Alcoholism, 49, 154-159.

Yoon, Y., \& Yi, H. (2008). Surveillance report no. 83: Liver cirrhosis mortality in the United States, 1970-2005. Washington,
DC: National Institute of Alcohol Abuse and Alcoholism, National Institutes of Health. Retrieved from http://pubs.niaaa.nih.gov/publications/surveillance83/Cirr 05.htm

Zwarun, L. (2006). Ten years and 1 master settlement agreement later: The nature and frequency of alcohol and tobacco promotion in televised sports, 2000 through 2002. American Journal of Public Health, 96(8), 1492-1497. 